Revista de Derecho

de la Pontificia Universidad Católica de Valparaíso

XXIX (Valparaíso, Chile, $2^{\text {do }}$ Semestre de 2007)

[pp. 119 - 140]

\title{
LAS ACCIONES CIVILES DERIVADAS DEL DAÑO AMBIENTAL EN LA LEY No 19.300
}

[Civil Actions Arising From Environmental Damage in Act No 19.300]

\author{
Álvaro Vidal Olivares* \\ Pontificia Universidad Católica de Valparaíso
}

\begin{abstract}
Resumen
Un daño ambiental puede producir como consecuencia directa e inmediata un daño civil, y él da lugar a las acciones de responsabilidad ambiental y de indemnización ordinaria. La Ley $\mathrm{N}^{\circ} 19.300$ prevé un régimen básico de común aplicación a ambas, que hace excepción a las normas del Derecho común . Entre los legitimados activos para la acción ambiental se cuentan las personas naturales o jurídicas que hayan sufrido un daño ambiental; y tiene por primer objeto una prestación de hacer: la reparación material del daño en la medida que sea posible. Sin embargo, cuando tal reparación material, en los términos previstos por la propia Ley, no es posible, se abre paso la indemnización de daños como una reparación en equivalencia.
\end{abstract}

Palabras Clave: Daño ambiental - Daño civil - Reparación.

\begin{abstract}
Environmental damage may directly and immediately result in civil damage that, in turn, will give rise to environmental liability and ordinary compensation actions. A basic regime of common application for both aforementioned actions, excluding the norms of common Law, is stipulated in Act No. 19.300. People or companies that have sustained environmental damage are among the active legitimated parties to take environmental action, object of which is material restoration as far as possible. However, according to this law, when said material restoration is not possible, damage compensation rises as an equivalent compensation.
\end{abstract}

KeYwords: Environmental damage - Civil damage - Compensation.

* Profesor de la Facultad de Derecho de la Pontificia Universidad Católica de Valparaíso. Dirección Postal: Facultad de Derecho, Pontificia Universidad Católica de Valparaíso, Avda. Brasil 2950, Casilla 4059, Valparaíso, Chile. Correo electrónico: alvaro.vidal@ucv.cl. El presente trabajo ha sido elaborado como parte del Proyecto Fondecyt No 1060818, cuyo investigador responsable es el profesor de Derecho ambiental de la Pontificia Universidad Católica de Valparaíso, D. Jorge Bermúdez Soto. 


\section{INTRODUCCIÓN}

La Ley $\mathrm{N}^{\circ} 19.300$ sobre Bases Generales del Medio Ambiente, en adelante, la Ley $\mathrm{N}^{\circ} 19.300$, establece, entre otras cosas, el principio de la responsabilidad por el daño ambiental, previendo reglas que constituyen en su conjunto un régimen especial o descodificado de responsabilidad civil, que se suple en sus lagunas por las normas del título $25^{\circ}$ del libro IV del Código Civil.

En este régimen, el origen de la responsabilidad está en una especie o clase de daño ignorado hasta la vigencia de la Ley $\mathrm{N}^{\circ} 19.300$, el daño ambiental, definido por su artículo 2, letra f). Hasta ese instante la lesión al medio ambiente o alguno de sus elementos, que en el hecho se producía, quedaba sin reparación. La responsabilidad del derecho común sólo alcanzaba a los daños patrimoniales y/o no patrimoniales que derivaban de tal lesión: daño emergente, lucro cesante, daño moral, etc. A estos daños le denominaré daño civil en oposición al daño ambiental.

Hoy en materia ambiental, como debe ser, rige el principio de la reparación integral que ordena que todo daño, cualquiera sea su naturaleza, debe ser reparado (artículos 2314 y 2329 CC.). Tanto el daño ambiental propiamente dicho, como el daño civil que deriva inmediatamente de él, integran el objeto de la responsabilidad, la que se manifiesta, como se verá, de distinta manera según la clase de daño de que se trate. Tratándose del daño ambiental, como reparación en naturaleza; en cambio, para el daño civil, en una indemnización. La víctima de un daño civil que proviene de un daño ambiental, puede ejercitar ambas acciones conjunta o separadamente; o conformarse con el ejercicio de la acción ordinaria por el daño civil, dejando de lado el de la acción ambiental. La víctima decide según sea su conveniencia, lo que no quiere decir que la protección al medio ambiente quede sujeta a la opción que tome el dañado civilmente, puesto que la titularidad de la acción ambiental es más amplia, recayendo además en el Estado, que la ejerce a través del Consejo de Defensa del Estado; y en las Municipalidades, a requerimientos de las personas que puedan verse afectadas por la causación de un daño ambiental (artículo 54 Ley No 19.300)

Como se señaló, la responsabilidad ambiental queda sometida al régimen de la Ley $\mathrm{N}^{\circ} 19.300$ y, en lo no previsto por ella, a las del título $35^{\circ}$ del libro IV del Código Civil (artículo 53, inciso 3o, Ley No 19.300). Tal régimen así integrado constituye el derecho común en materia de responsabilidad ambiental ${ }^{1}$ y un régimen especial con relación al derecho

${ }^{1}$ Así lo ha resuelto la Corte Suprema, en sentencia de 30 de agosto de 2006, en 
común del Código Civil. En lo que concierne a la responsabilidad por el daño civil originado por la lesión al medio ambiente o alguno de sus componentes, se sujeta al régimen del derecho común, pero con algunas excepciones contenidas en la propia Ley No 19.300 , pudiendo sostenerse que para ambas responsabilidades -la estrictamente ambiental y la civil ordinaria- hay un régimen primario o básico que se concreta en reglas de aplicación común.

Pese a la clara división entre la responsabilidad ambiental y la civil ordinaria por daños, cuando se acude a la doctrina especializada, puede observarse una cierta confusión a la hora de precisar la exacta relación existente entre ambos órdenes de responsabilidad; tanto en lo que concierne al supuesto de concurrencia de responsabilidades que prevé la Ley y somete a normas especiales; a la titularidad de la acción ambiental; y a la responsabilidad ambiental cuando no es posible la reparación en naturaleza del daño.

Consiguientemente, este trabajo lo dividiré en dos partes. En la primera me ocuparé de la relación existente entre la responsabilidad ambiental y la originada por el daño civil que pueda experimentar una persona con ocasión de la producción de un daño ambiental, fijando el supuesto que prevé la Ley y destacando su importancia desde la óptica del régimen aplicable. En la segunda, me ocuparé de dos cuestiones a que da lugar la responsabilidad ambiental, relacionadas con la responsabilidad del derecho común; a saber, el de la legitimación activa de la acción ambiental; y, posteriormente, el de la procedencia, o no, de la indemnización del derecho común cuando sea imposible la reparación en naturaleza del daño ambiental. Finalizaré con unas conclusiones.

la que se lee: "La Ley $N^{\circ} 19.300$ es inaplicable sólo en los casos en que exista una Ley especial que incluya reglas sobre responsabilidad por daño ambiental. Pues bien, la Ley $N^{\circ} 17.288$ contiene normas sobre dicho aspecto pero unicamente referidas a sanciones penales o administrativas, estableciendo en el artículo 38 que ello es sin perjuicio de la responsabilidad civil que les afecte a los infractores. Entonces, para hacer efectiva la responsabilidad civil de estos últimos, necesariamente debe aplicarse la Ley $N^{\circ} 19.300$, y en lo no previsto por ella, las normas del Código Civil" (Número de Identificador LexisNexis: 35145).

${ }^{2}$ Cfr. con Bermúdez Soto, J., Fundamentos de Derecho Ambiental (Valparaíso, 2007), p. 224; y Corral TALCIANI, H., Lecciones de responsabilidad extracontractual (Santiago, 2004), p. 264. Ambos reconocen que si bien el régimen de la Ley No 19.300 constituye en derecho común en materia ambiental, respecto del Derecho Civil es derecho especial y se suple por las normas del título $35^{\circ}$ del libro IV del Código Civil. 


\section{RESPONSABILIDAD POR DAÑO AMBIENTAL Y POR DAÑO CIVIL}

La Ley No 19.300 consagra el principio que se ha ido acuñando en los ordenamientos jurídicos, cual es, el de la responsabilidad ambiental que se traduce en la máxima: "el que contamina paga", anticipando, desde ya, que el legislador nacional lo modifica levemente, consagrándolo en términos de "quien contamina debe reparar materialmente a su costo el daño causado" "Se trasladan los costos de la reparación del daño ambiental desde la sociedad toda hasta los operadores que lo causan con ocasión del desarrollo de una actividad que cede exclusivamente en su benefició ${ }^{4}$.

El artículo 51 prescribe que todo el que dolosa o culposamente cause daño ambiental responderá del mismo de conformidad a la presente Ley. Y el artículo 3, explicitando en qué consiste esta responsabilidad prescribe que "todo el que culposa o dolosamente cause daño al medio ambiente, estará obligado a repararlo materialmente, a su costo, si ello fuere posible e indemnizarlo conforme la Ley".

$\mathrm{Al}$ autor del daño se le obliga a una reparación en naturaleza, a una reparación estrictu sensu, y que se la define como una "acción de reponer el medio ambiente o uno o más de sus componentes a una calidad similar a la que tenían con anterioridad al daño causado o, en caso de no ser ello posible, reestablecer sus propiedades básicas" (artículo 2 letra s) Ley No 19.300). El objeto inmediato de la acción ambiental es una condena de hacer: reponer el medio ambiente lesionado o, en caso de no ser posible, reestablecer sus propiedades básicas.

El daño ambiental implica una lesión al medio ambiente o a alguno de sus componentes, entendido como bien jurídico colectivo y cuyo último titular es el Estado, que por mandato constitucional tiene el deber de

${ }^{3}$ Así se infiere de los artículos 20, letra s), y 30 Ley No 19.300 .

${ }^{4}$ Véase: Valenzuela Fuenzalida, R., Nociones acerca del principio "El que contamina paga", en Memoria del Seminario de Derecho Ambiental (Santiago, 1994); y El que contamina paga, en Revista de la CEPAL 45. Una explicación del principio desde el análisis económico en: De La BARra Gili, F., Responsabilidad extracontractual por daño ambiental: el problema de la legitimación activa, en RChD. 29 (2002) 2, p. 370. En el Preámbulo de la Ley No 26/ 2007 (Responsabilidad medioambiental), de 23 de octubre (en $B O E$. No 255, p. 43.229), que traspone, en el ordenamiento español, la Directiva 2004/ 35/ CE, de 21 de abril de 2004. Se declara expresamente que ella instaura el principio de quien contamina paga y el artículo 1 sobre el objeto de la Ley dispone expresamente: "esta Ley regula la responsabilidad de los operadores de prevenir, evitar y reparar los daños medioambientales, de conformidad con el articulo 45 de la Constitución y con los principios de prevención y de que "quien contamina paga". 
preservar el medio ambiente y así asegurar el derecho de todos a vivir en un medio ambiente libre de contaminación. Quiere decir que una acción u omisión puede lesionar el medio ambiente y hacer nacer exclusivamente la acción ambiental para obtener la reparación del daño. En este caso sólo estaría comprometido el interés colectivo de preservación del medio ambiente.

No obstante lo anterior, la Ley considera la posibilidad que el daño ambiental lesione otros bienes jurídicos, ahora de titularidad individual, causando daño civil a la persona o propiedad de otro. Nace entonces la responsabilidad ambiental y la del derecho común, reconociéndose que ambas responsabilidades son perfectamente compatibles.

Hasta antes de la Ley No 19.300 cuando una acción u omisión causaba un daño ambiental, únicamente podía perseguirse la responsabilidad derivada del daño civil -daños en la persona y su propiedad- del título $35^{\circ}$ del libro IV del Código Civil, quedando sin protección el bien jurídico directamente lesionado: el medio ambiente y los elementos que lo componen, bien jurídico que contaba con reconocimiento constitucional ${ }^{5}$ desde el año $1980^{6}$. En la doctrina hay quien sostiene que con el ejercicio de la acción ordinaria se lograba una protección mediata del medio ambiente, porque la víctima demandante podía solicitar se decretaran medidas que

${ }^{5}$ La Constitución Política de 1980 consagró, en su artículo 19, No 8, el derecho a vivir en un medio ambiente libre de contaminación, imponiendo al Estado el deber de preservarlo; y al mismo tiempo, su artículo 20, cauteló este derecho mediante una acción constitucional de protección que exige que sea afectado por actos u omisiones ilegales imputables a una autoridad o persona determinada. Sobre las distintas técnicas e instrumentos de protección del medio ambiente, véase: BERmúdez Soto, J., cit. (n. 2); y Barros Bourie, E., Tratado de la responsabilidad extracontractual (Santiago, 2006), pp. 789-798.

${ }^{6}$ Hasta antes de la Ley No 19.300, habían algunos instrumentos aislados de protección del medio ambiente. Así, por ejemplo, el artículo 937 del Código Civil reconoce una especie de acción popular no sujeta a prescripción en contra de obras que corrompan el aire y lo hagan conocidamente dańoso. La primera Ley referida al medio ambiente fue una dictada el año 1916 que regulaba la contaminación de aguas destinadas a la bebida y el riego (Ley $\mathrm{N}^{\circ} 3.133$ ). A ella se agrego a mediados del siglo $\mathrm{XX}$ varias leyes especiales referidas a riesgos específicos, como las que implican la actividad nuclear (Ley N $N^{\circ} 18.302$ de Seguridad Nuclear) y el de derrame de hidrocarburos (artículo 144 del DL. № 2222 de 1978, Ley de navegación). Estos regímenes especiales, como sostiene acertadamente Bermúdez, no establecen una responsabilidad estrictamente ambiental, sino que reconocen una acción indemnizatoria por el daño civil que resulte de estas actividades. Se lee en su obra: "En consecuencia, más que tratarse de una responsabilidad ambiental especial, en estricto rigor, se trataría de una responsabilidad civil extracontractual nacida a partir de un daño ambiental" [Bermúdez Soto, J., cit. (n. 2), p. 224]. 
hicieran cesar la causa del daño civil, esto es, el propio daño ambiental. Se confunden dos cosas, la cesación del daño civil con la reparación del daño ambiental en sí mismo. El hacer cesar un daño ambiental no implica su reparación, sino sencillamente aquello, su cesación ${ }^{7}$.

Hoy, tras la Ley No 19.300 que reconoce una acción para la reparación del daño ambiental, la protección es plena, comprendiendo todos los intereses lesionados, tanto los de titularidad colectiva como individual ${ }^{8}$. Se alcanza la realización del principio de la reparación integral dado que se cubre todo daño, independientemente de su naturaleza. Reparación plena que implica el ejercicio de dos acciones diversas, la que persigue la reparación en naturaleza del daño ambiental; y la ordinaria, cuya finalidad es la indemnización de los daños a la propiedad y la persona de otro?.

El artículo 53 prevé en forma expresa la posible concurrencia de responsabilidades: la ambiental y la derivada del daño civil irrogado. $\mathrm{Y}$ el artículo 63 sobre la prescripción reconoce que de un daño ambiental pueden nacer acciones civiles, en la especie, la de responsabilidad ambiental y la del derecho común por delito o cuasidelito civil ${ }^{10}$.

${ }^{7}$ En esa confusión: De La Barra Gili, F., cit. (n. 4).

${ }^{8}$ Como afirma Bermúdez Soto, J., cit. (n. 2), p. 224: “A partir de la entrada en vigor de la LGBMA la responsabilidad del causante de daños ambientales podrá ser perseguida ante los tribunales, a través de una acción general y especialmente diseñada para el efecto".

${ }^{9}$ Cfr. Corral Talciani, H., cit. (n. 2), p. 263. La Corte de Apelaciones de Valparaíso, en sentencia de 26 de julio del año 2000 , reconoció que se trata de acciones de diversa naturaleza y objeto, declarando: "En ese sentido debe entenderse lo estatuido en artículo 53 de la Ley $N^{\circ}$ 19.300, sobre Bases Generales del Medio Ambiente en cuanto dispone que producido el daño ambiental, se concede acción para obtener la reparación del medio ambiente dañado, lo que no obsta al ejercicio de la acción indemnizatoria ordinaria por el directamente afectado (Identificador LexisNexis $\mathrm{N}^{\circ} 18.470$ ).

${ }^{10}$ En la reciente Ley española (No 26/ 2007 Responsabilidad medioambiental) se reconoce que de los daños medioambientales pueden derivar daños particulares (civiles), sin embargo, excluye completamente del ámbito de la Ley la responsabilidad por esta última clase de daños, que se sujetará a las normas del Código Civil. Agrega que la reclamación de la indemnización de los dańos particulares no exonera al operador que contamina de su obligación de evitar y reparar los daños medioambientales. El artículo 5 de la citada Ley dispone: "Daños a particulares. 1. Esta Ley no ampara el ejercicio de acciones por lesiones causadas a las personas, a los daños causados a la propiedad privada, a ningún tipo de pérdida económica ni afecta a ningún derecho relativo a este tipo de daños o cualesquiera otros daños patrimoniales que no tengan la condición de daños medioambientales, aunque sean consecuencia de los mismos hechos que dan origen a responsabilidad medioambiental. Tales acciones se regirán por la normativa que en cada caso resulte de aplicación. 2. Los particulares perjudicados a que se refiere el apartado anterior no podrán exigir reparación ni indemnización por los daños medioambientales que se les hayan irrogado, en la medida en la que tales daños queden reparados 
Interesa determinar cuál es el supuesto a que se refiere el precepto porque la Ley No 19.300 somete la responsabilidad por el daño civil que deriva del daño ambiental a un régimen que hace excepción al derecho común del título $35^{\circ}$ del libro IV del Código Civil ${ }^{11}$.

En la práctica pueden presentarse dos supuestos diversos. El primero, aquél en que un mismo hecho ilícito causa un daño ambiental y un daño civil. Así, cuando un conductor negligente atropella a un peatón y se estrella contra un edificio que goza de protección oficial según la Ley de monumentos, destruyéndolo. El segundo, el daño civil es una consecuencia directa e inmediata del daño ambiental. Por ejemplo, el conductor de un camión que traslada un cargamento de hidrocarburo, pierde el control de su vehículo y lo vuelca en una zona agrícola provocando un importante derrame que produce un daño ambiental consistente en la contaminación de las napas subterráneas y el exterminio de las especies de la zona; y, al mismo tiempo, causa un daño civil a los agricultores del sector consistente en daño emergente; pérdida de ganancias y daños a la salud por la ingesta de agua contaminada.

El daño civil que importa a los efectos del régimen especial de la Ley No 19.300 es el del segundo caso, que emana directa e inmediatamente del daño ambiental. A este daño se refiere el artículo 63 cuando alude a las acciones civiles emanadas del dańo ambiental. Como se ha dicho, una de ellas es la propiamente ambiental y la otra, es la ordinaria de indemnización $^{12}$. Es el daño ambiental el que genera el daño civil ${ }^{13}$.

De forma que en el primer supuesto, como hay daño ambiental y daño civil desvinculados entre sí, pero con idéntica causa, surgirá responsabilidad ambiental regida por la Ley No 19.300 y responsabilidad civil

por la aplicación de esta Ley. El responsable que hubiera hecho frente a esa doble reparación podrá reclamar del perjudicado la devolución o la compensación que proceda. 3. En ningún caso las reclamaciones de los particulares perjudicados en cualesquiera procesos o procedimientos exonerarán al operador responsable de la adopción plena y efectiva de las medidas de prevención, de evitación o de reparación que resulten de la aplicación de esta Ley ni impedirán las actuaciones administrativas encaminadas a ello".

${ }^{11}$ Barros Bourie, E., cit. (n. 5), p. 800, afirma: "Las reglas que rigen la acción indemnizatoria son esencialmente las mismas que las aplicables a la acción ambiental".

${ }^{12}$ Tratándose del daño ambiental, el responsable queda obligado a su reparación material (reparación en naturaleza); en cambio, el daño civil da lugar a una indemnización (reparación en equivalente).

${ }^{13}$ Barros Bourie, E., cit. (n. 5), p. 798, expresa: "Lo peculiar es que el daño se produce a consecuencia de dańos ambientales, esto es, a causa de pérdidas, disminuciones, detrimentos o menoscabos significativos al medio ambiente o a alguno de sus componentes". En el mismo sentido: De La Barra Gili, F., cit. (n. 4), p. 384. 
sometida exclusivamente a las disposiciones del Código Civil. Para hacer efectiva la responsabilidad por el daño civil irrogado se parte del hecho causal, la negligencia del conductor, sin importar si se causó o no un daño ambiental.

La víctima del daño civil, podrá ejercitar su acción ordinaria de indemnización, sea conjuntamente con la acción ambiental, en el mismo juicio sumario del artículo 61; sea en forma separada en juicio ordinario ${ }^{14}$. Si bien ésta es una opción que pertenece al actor, la aplicación de la regla de legitimación del artículo 54 de la Ley $\mathrm{N}^{\circ} 19.300$, puede impedir el ejercicio de la acción por el daño civil en el juicio en que se intenta hacer efectiva la responsabilidad ambiental. Pienso en la hipótesis en que la acción ambiental la ejercita el Estado a través del Consejo de Defensa del Estado o la Municipalidad correspondiente. Como se verá, en este caso se excluye el ejercicio por parte de quien sufrió el daño o perjuicio, pudiendo sólo intervenir en el juicio como tercero coadyuvante, en los términos del artículo 23 del Código de Procedimiento Civil.

En síntesis, de un mismo hecho que causa daño ambiental, pueden nacer tres acciones diversas, la acción ambiental propiamente dicha; la acción indemnizatoria del daño civil que emana directamente del daño ambiental; y una acción de responsabilidad sancionatoria sea administrativa o judicial ${ }^{15}$.

Como anuncié al principio, la Ley No 19.300 prevé un régimen básico aplicable a ambas responsabilidades caracterizado por: i) si bien el régimen de responsabilidad que prevé la Ley sigue apoyándose en la culpa o dolo del agente del daño, su artículo 52 establece una presunción de culpa por infracción de las normas ambientales, haciendo responsable al que la comete siempre que se acredite la relación de causalidad entre la infracción y el daño ${ }^{16}$. Se prevé una culpa infraccional que se da por acreditada con la sola prueba de la contravención de la norma ${ }^{17}$. El sistema sigue siendo

${ }^{14} \mathrm{La}$ Corte Suprema se ha pronunciado en contra, rechazando el ejercicio conjunto de ambas acciones. Véase la Sentencia de la Corte Suprema de 25 de abril de 2001 (Número Identificador LexisNexis: 18470).

${ }^{15}$ Cfr. Bermúdez Soto, J., cit. (n. 2), p. 225.

${ }^{16}$ Para un estudio sobre la culpa en la responsabilidad ambiental, véase: HUNTER Ampuero, I., La culpa con la Ley en la responsabilidad civil ambiental, en RdUACh. 18 (2005) 2, pp. 9-25.

${ }^{17}$ Debe precisarse que de esta norma no puede inferirse que la responsabilidad ambiental se fundaría en la ilegalidad del acto u omisión que causa daño, sino que en la culpa, importando no sólo la observancia de la norma, sino también la observancia de los deberes generales de cuidado, propios de la responsabilidad civil extracontractual. Así se desprende claramente de la historia del establecimiento de la Ley y lo confirma el propio artículo 54 de la Ley que por excepción exonera de responsabilidad 
subjetivo $^{18}$; no hay que olvidar que en la doctrina del derecho civil se encuentra acuñada la noción de culpa por infracción de norma ${ }^{19}$; ii) según el artículo 63 la prescripción de las acciones civiles derivadas de daño ambiental (la ambiental y la de ordinaria de indemnización) es de cinco años contados desde la manifestación evidente del daño. La Ley resuelve, en consecuencia, la antigua discusión hoy superada en la doctrina, no así del todo en la jurisprudencia, sobre el alcance del artículo 2332 del Código Civil en lo que concierne al momento en que empieza a computarse el plazo de cuatro años que la norma prevée ${ }^{20}$. Lo relevante para la

ambiental cuando se acredite el cumplimiento de la norma. Así lo reconoce y lo trata detenidamente: Barros Bourie, E., cit. (n. 5.), pp. 800-803; y Hunter Ampuero, I, cit. (n. 17), p. 23. En contra: De La Barra Gili, F., cit. (n. 4), pp. 391 y 392 . El autor concluye que no habría responsabilidad ambiental por acto legal o ajustado a la norma y llega a esta conclusión generalizando lo preceptuado por el artículo 54.

${ }^{18}$ En la doctrina de derecho ambiental Bermúdez Soto, J., cit. (n. 2), p. 232, sostiene que dada la amplitud del ámbito de aplicación de la presunción del artículo 52 la Ley permitiría el tránsito desde una responsabilidad subjetiva a una objetivada, dado que la carga de la prueba recaería sobre el elemento objetivo, a saber, la infracción de la norma.

${ }^{19}$ Corral Talciani, H., cit. (n. 2), p. 215, afirma que el deber de cuidado, de actuar con diligencia o prudencia, se ha explicitado en normas o reglamentos, que en forma expresa señalan cuál es el comportamiento cuidadoso exigido, el hecho de que el agente transgreda con su conducta la norma expresada da pie para considerar que ha existido culpa en su actuación.

${ }^{20}$ Para Alessandri Rodríguez, A., De la responsabilidad extracontractual en el Derecho Civil chileno (Santiago, 1943), pp. 522 y 523, el plazo de prescripción del artículo 2332 del Código Civil se cuenta desde "el día en que se cometió el hecho doloso o culpable y no desde aquel en que se produjo el daño, si éste y el hecho no son coetáneos". Le siguen: Somarriva Undurraga, M., Las obligaciones y los contratos ante la jurisprudencia (2a edición actualizada por Domínguez Águila, R., Santiago, 1984), p. 380, y Tapia SuÁrez, O., De la responsabilidad civil en general y de la responsabilidad delictual entre los contratantes (Concepción, 1941, en reimpresión a cargo de Diez Schwerter, J., Santiago, 2006), p. 318 ss. En contra, superando la interpretación literal del precepto: Abeliuk ManASEVICH, R., Las obligaciones (Santiago, 2003), I, pp. 291 ss.; Barros Bourie, E., cit. (n. 5), pp. 293 ss.; Corral Talciani, H., cit. (n. 2), p. 350; Domínguez Águila, R., La prescripción extintiva. Doctrina y jurisprudencia (Santiago, 2004), pp. 377 ss. Estos autores coinciden en que si el daño se hace manifiesto en un momento posterior a la verificación del hecho lícito, el plazo de prescripción debe contarse desde la manifestación del daño. La Corte Suprema el 19 de abril de 2005 resuelve que la prescripción debe contarse desde la manifestación del daño y no antes. En ella se lee que "la doctrina nacional está conteste en que el plazo de prescripción de la acción indemnizatoria [...] se cuenta desde que se perpetra el acto, esto es, desde que se consuma" $y$ fundando su resolución transcribe un consi- 
Ley $\mathrm{N}^{\circ} 19.300$ es la manifestación del daño, que es el momento en que concurren los elementos de la responsabilidad civil que la hacen nacer $y$, por consiguiente, puede sancionarse la pasividad de los legitimados para el ejercicio de las acciones civiles que emanan del daño ambiental; iii) El artículo 60 establece una regla de competencia excepcional, confiriendo a la víctima la elección entre demandar ante el juez del lugar en que se origina el hecho que causa el daño o aquél del domicilio del demandado; iv) Las acciones, en caso de ejercitarse conjuntamente, se someten a las reglas del juicio sumario con las particularidades que el propio artículo 61 establece para la prueba de peritos ${ }^{21}$. Y, finalmente, v) según el artículo 62, el juez apreciará las pruebas rendidas de acuerdo a las reglas de la sana crítica y será admisible cualquier medio de prueba sin limitarse a los que prevé el Código de Procedimiento Civil.

Finalmente, cabe consignar que la posibilidad de ejercer la acción con-

derando de la sentencia de la misma Corte Suprema de 1 de agosto de 1967 que expresa: "Que, como consecuencia de lo dicho anteriormente, debe entenderse que el momento inicial, desde el cual comienza a correr la prescripción especial de corto tiempo establecida en el artículo 2332 del Código Civil, es aquel en que se produjo el daño consecuencial a la realización, por parte del autor, de un delito o cuasidelito, pues la expresión 'perpetración del acto', usada en él, tiene el significado amplio de realización de una acción que provoca causalmente un dańo indemnizable" (Identificador LexisNexis Nº 32041).

${ }^{21} \mathrm{La}$ Corte Suprema se ha pronunciado en contra resolviendo que no corresponde el ejercicio conjunto y la aplicación de las reglas del juicio sumario, dado que la acción de indemnización es una acción ordinaria y como tal debe quedar sometida a las reglas del juicio ordinario. El sentenciador se apoya principalmente en el tenor literal del artículo 53 que alude a la acción ordinaria de indemnización, de lo que deduce que tal acción, dada su naturaleza, sólo debe incoarse en un juicio ordinario. En la sentencia se lee: "Si bien es cierto que el tribunal, ante el cual se entablaron conjuntamente una acción para obtener la reparación del medio ambiente dañado con otras acciones indemnizatorias, es competente para conocer la acción de reparación del daño ambiental en procedimiento sumario, no lo es menos que no existe regla expresa en la Ley $N^{o} 19.300$ que otorgue a los perjudicados directamente con el daño ambiental acciones indemnizatorias en el mismo procedimiento sumario, de manera que respecto de esas acciones debe estarse a lo dispuesto en las reglas generales, siendo improcedente la tramitación conjunta de ambas acciones en el mismo procedimiento; por lo cual, debe acogerse la nulidad de todo lo obrado en estos autos" (véase la Sentencia Corte Suprema, de 25 de abril de 2001, Número Identificador LexisNexis: 18470). En verdad, si se tiene en cuenta lo que dispone el artículo 61 que somete al juicio sumario a todas las acciones a que dé lugar la infracción de la Ley $\mathrm{N}^{\circ} 19.300$ y que el supuesto relevante para la Ley es aquél en el que el daño civil emana directa e inmediatamente del daño ambiental, puede concluirse que la referencia legal al carácter ordinario de la acción indemnizatoria debe entenderse hecha a que se trata de una acción del derecho común en oposición a la acción especial ambiental. 
juntamente con la acción ambiental, además de verse afectada por la regla de la legitimación, podría no interesarle a la propia víctima del daño civil derivado del daño ambiental, prefiriendo demandar conforme el estatuto de derecho común de la responsabilidad por culpa del Código Civil. La aplicación de las normas primarias o básicas de la Ley $\mathrm{N}^{\circ} 19.300$ presuponen la prueba del daño ambiental, la que puede en ocasiones tornar muy compleja y, además, costosa; pudiendo peligrar el derecho a la reparación del daño civil por no concurrir el presupuesto, el daño ambiental.

\section{LOS PROBLEMAS. LA LEGITIMACIÓN ACTIVA Y REPARACIÓN EN EQUIVALENCIA}

En este apartado, como lo anticipé, me ocuparé de dos cuestiones a que da lugar la responsabilidad ambiental, ambas relacionadas con la responsabilidad del derecho común; a saber, la de la legitimación activa de la acción ambiental; y la de la procedencia, o no, de la indemnización del derecho común cuando sea imposible la reparación en naturaleza del daño ambiental.

\section{La legitimación activa en la responsabilidad ambiental2 .}

Cuando se habla de la legitimación activa y de las reglas de la Ley $\mathrm{N}^{\circ}$ 19.300 que la gobiernan, se alude a la acción ambiental y no a la que nace del daño civil, puesto que la legitimación de ésta se rige por el derecho civil, esto es, es titular de la acción quien invoque y acredite la lesión de un interés legítimo de la que se siguen consecuencias de daño en su persona o patrimonio.

La naturaleza del interés tutelado -el derecho a vivir en un medio ambiente libre de contaminación- y el deber constitucional que pesa sobre el Estado, justifica la regulación especial de la legitimación activa de la acción ambiental; la que debe asegurar la debida protección de tal interés cuando resulte efectivamente lesionado por una acción u omisión de otro, imputable a su dolo o culpa. Sin embargo, esta protección debe considerar todos los intereses en juego, evitándose los abusos y falta de seriedad en el ejercicio de las acciones ambientales. Es esencial la labor del juez al dar o no por satisfecha esta exigencia de legitimación.

El artículo 54 de la Ley No 19.300 define quiénes pueden ejercer la acción ambiental con el único objeto de obtener la reparación del daño ambiental y la norma prescribe: "Son titulares de la acción ambiental señalada

${ }^{22}$ Sobre la legitimación activa en materia de responsabilidad ambiental, véase especialmente: Bordalí Salamanca, A., Tutela Jurisdiccional del Medio Ambiente (Valdivia, 2005), pp. 243-313; y De la Barra, F., cit. (n. 8). 
en el artículo anterior, y con el solo objeto de obtener la reparación del medio ambiente dañado, las personas naturales o jurídicas, públicas o privadas, que hayan sufrido el daño o perjuicio, las municipalidades, por los hechos acaecidos en sus respectivas comunas, y el Estado, por intermedio del Consejo de Defensa del Estado. Deducida demanda por alguno de los titulares señalados, no podrán interponerla los restantes, lo que no obsta a su derecho a intervenir como terceros. Para los efectos del artículo 23 del Código de Procedimiento Civil, se presume que las municipalidades y el Estado tienen interés actual en los resultados del juicio./Cualquier persona podrá requerir a la municipalidad en cuyo ámbito se desarrollen las actividades que causen daño al medio ambiente para que ésta, en su representación y sobre la base de los antecedentes que el requirente deberá proporcionarle, deduzca la respectiva acción ambiental. La municipalidad demandará en el término de 45 días, y si resolviere no hacerlo, emitirá dentro de igual plazo una resolución fundada que se notificará al requirente por carta certificada. La falta de pronunciamiento de la municipalidad en el término indicado la hará solidariamente responsable de los perjuicios que el hecho denunciado ocasionare al afectado".

Las reglas que da el artículo 54 son consecuentes con la naturaleza del bien jurídico tutelado en la responsabilidad ambiental, el derecho de todos los ciudadanos a vivir en un medio ambiente libre de contaminación, bien jurídico o interés de titularidad colectiva y difusa.

La Ley fija las condiciones que deben concurrir para ejercitar la acción ambiental. Entonces, los que pueden ejercitar la acción ambiental, iniciando un juicio de responsabilidad ambiental son: i) las personas naturales o jurídicas, públicas o privadas, que hayan sufrido el daño o perjuicio; ii) el Estado a través del Consejo de Defensa del Estado; y iii) las Municipalidades en cuyo ámbito se desarrollen las actividades que causen daño al medio ambiente, actuando siempre a requerimiento y en representación de cualquier persona.

En este último caso, la Ley prevé una verdadera acción popular indirecta cualquier persona, actuando la Municipalidad como verdadero filtro e incurriendo en responsabilidad para con el particular si no actúa conforme lo dispone la disposición.

El ejercicio de la acción ambiental por parte de cualquiera de los legitimados activos excluye a los restantes, quienes sólo podrán actuar en el juicio como terceros coadyuvantes. En el caso del Estado y las Municipalidades la Ley presume el interés, en cambio si se trata de la persona que alega haber sufrido un daño o perjuicio, deberá acreditar su interés actual en los resultados del juicio. La Ley descarta un supuesto de pluralidad de demandantes ${ }^{23}$.

${ }^{23}$ Cfr. Corral Talciani, H., cit. (n. 2), p. 263. 
La cuestión a que da lugar la disposición se refiere al primer legitimado activo, "las personas naturales o jurídicas, públicas o privadas, que hayan sufrido el daño o perjuicio". Una interpretación tradicional del Derecho Civil conduce a la conclusión que este primer grupo de legitimados activos para ejercer la acción ambiental está representado por aquellas personas, naturales o jurídicas, que experimentaron un daño civil ${ }^{24}$; restringiéndose al máximo la legitimación activa de estos sujetos, siendo más bien una regla de carácter excepcional ${ }^{25}$. De esta forma, sólo quien acredite la lesión de un interés individual de que es titular podría ejercer la acción para obtener la reparación del daño ambiental. La titularidad de la acción civil indemnizatoria absorbería a la de la acción ambiental, al entender que el precepto se refiere al daño civil y no al ambiental.

La otra interpretación consiste en entender que la norma entrega la acción ambiental a quien efectivamente sufrió el daño ambiental. Así, la legitimación activa coincidiría con la del derecho común, exigiéndose igualmente la lesión de un interés legítimo, el derecho a vivir en un medio ambiente libre de contaminación.

Para dar solución a esta cuestión debe considerarse la marcada diferenciación de la responsabilidad ambiental de aquélla que nace por el daño civil; y, además, que el interés en juego es uno de titularidad colectiva y difusa y que al mismo tiempo integra la esfera de cada individuo al concretarse como uno de sus derechos fundamentales (artículo 19. No 8 CPol.). Esta titularidad especial explica que la Ley confiera primeramente el ejercicio de la acción ambiental a las personas naturales y jurídicas, de derecho público o privado que hayan sufrido el daño ambiental; acción que se ejercitaría en beneficio propio y también de la colectividad toda afectada por el accidente ambiental.

Entre las razones en que puede apoyarse esta última interpretación a la que adhiero y que cuenta con el apoyo de la mayoría de la doctrina, me interesa destacar las siguientes:

i) Si se considera que es una opción para la víctima el ejercer la acción

${ }^{24}$ Así pareciere entenderlo el profesor Barros cuando alude a la naturaleza privada de la titularidad de la acción ambiental, cuando se trata de las personas -naturales o jurídicas, públicas o privadas- que hayan sufrido el daño. Barros Bourie, E., cit.(n. 5), p. 810. Con una opinión similar, véase a: Corral Talciani, H., ibíd.

${ }^{25}$ Cfr. Bermúdez Soto, J., cit. (n. 2), p. 246. El autor explica que desde esta interpretación tradicional "estos legitimados activos contarán con dos acciones: su acción indemnizatoria ordinaria, para perseguir la reparación de los perjuicios de carácter "no ambiental", es decir, los perjuicios individuales que se traducen en daños a la persona o patrimonio. Y la acción ambiental, destinada a la reparación (...) del entorno dañado". 
civil ordinaria conjuntamente con la ambiental; y también la exclusión prevista para el caso que la acción la ejercite primeramente el Estado o una Municipalidad, no tendría sentido el forzar en el juicio ambiental la prueba del daño civil para justificar la legitimación activa, en circunstancias que la víctima podría no estar interesada pedir su indemnización en ese juicio o bien porque la pretensión de indemnización ha quedado excluida por haberse ejercido primero la acción ambiental por otro de los legitimados. En este último caso, la intervención como tercero, como se sabe, exige acreditar un interés actual en los resultados del juicio. Si se sostiene que la norma se refiere al daño civil y no al ambiental, quien quisiera intervenir como tercero en el juicio debiese acreditar el daño de la primera clase, a pesar de que no tiene posibilidad alguna de demandar su indemnización en ese juicio.

ii) Habrá casos, los que no serán pocos, en los que del daño ambiental no se seguirá un daño civil. Si se entiende que la norma asocia la legitimación activa con el daño civil, querría decir que en estos casos, sólo podría ejercer la acción ambiental, o el Estado o una municipalidad; quienes en muchas ocasiones no estarán verdaderamente interesados en ejercerla, por razones económicas o políticas; o bien por ser el propio Estado el que causó el daño ambiental ${ }^{26}$.

iii) Finalmente, no será poco frecuente que si bien el daño producirá detrimentos o pérdidas patrimoniales o no patrimoniales, éstos no revistirán la necesaria significación como para constituir daño civil, pero sí daño ambiental. Aquí nuevamente quedaría excluida la legitimación de personas que pese a no experimentar un daño civil, sí sufren o están afectados por un daño ambiental.

Queda pendiente definir cuándo se entiende que una persona sufre un daño ambiental o no.

Siguiendo a Bermúdez, para concluir que una persona sufre un daño ambiental deberá existir un cierto grado de vinculación entre la persona natural o jurídica, que sin tener necesariamente un interés en una indemnización ordinaria, considera que el daño al medio ambiente le afecta, para lo cual recurre a la tesis del entorno adyacente ${ }^{27}$. En consecuencia no

${ }^{26}$ Véase: Bermúdez Soto, J., La responsabilidad extracontractual de la Administración del Estado por falta de servicio y por el daño ambiental, en RDUCV. 23 (2002), pp. 244-256. En un sentido similar: De la Barra, F., cit. (n. 8), pp. 391-392; y Bordalí Salamanca, A., pp. 261-283.

${ }^{27}$ Bermúdez Soto, J., cit. (n. 2), p. 81 explica que el "entorno adyacente" es "el lugar necesario para que el individuo se desarrolle, es decir, el espacio que él necesita para poder desplegar sus capacidades, en definitiva el entorno relacionado al individuo, necesario para alcanzar la mayor realización espiritual y material posible, 
se trata de una acción popular con legitimados activos amplios, porque el que sufre directamente un dańo ambiental es quien sufre una pérdida o deterioro del medio ambiente que le es adyacente ${ }^{28}$.

En síntesis, cuando la Ley alude a las personas que sufrieron el daño o perjuicio, lo hace a quienes por ser víctima de un daño ambiental están interesados en su reparación ${ }^{29}$, puesto que ésta es la que les permitiría hacer realidad el derecho constitucional de vivir en un medio ambiente libre de contaminación, conculcado por una acción u omisión dolosa o culposa.

De esta interpretación se siguen ciertas restricciones para las víctimas del daño civil que intentan la acción de indemnización en el juicio ambiental, dado que primeramente deberán estar legitimados para el ejercicio de la acción ambiental, debiendo justificar haber sufrido un daño de dicha naturaleza. Ello concuerda con lo expresado en la primera parte, en el sentido que el ejercicio de la acción por daño civil según el estatuto de la Ley $\mathrm{N}^{\circ} 19.300$ presupone la prueba del daño ambiental.

que asegura el artículo 1 inc. $4^{\circ}$ CPR." Y agrega: "dicho entorno influye directa o indirectamente en forma previsible en esa esfera más próxima que está representada por su domicilio y lugar de trabajo, la cual viene protegida por otros derechos distintos del derecho a vivir en un medio ambiente libre de contaminación, por ejemplo, los derechos a la vida, a la intimidad, a la inviolabilidad del domicilio, de propiedad, a la salud, etc.".

${ }^{28}$ Ibíd, p. 247.

${ }^{29}$ Conviene tener presente que la Ley española de responsabilidad medioambiental considera entre los legitimados para iniciar un procedimiento de exigencia de esta responsabilidad a los interesados distintos a los operadores que causan el daño y define a quiénes se entenderá por tales. El artículo 42 de la Ley prescribe: "Interesados. 1. Tendrán la condición de interesados a los efectos de lo previsto en esta Ley : a) Toda persona fisica o jurídica en la que concurra cualquiera de las circunstancias previstas en el artículo 31 de la Ley 30/1992, de 26 de noviembre. b) Cualesquiera personas jurídicas sin ánimo de lucro que acrediten el cumplimiento de los siguientes requisitos: 1. ${ }^{\circ}$ Que tengan entre los fines acreditados en sus estatutos la protección del medio ambiente en general o la de alguno de sus elementos en particular. 2. Que se hubieran constituido legalmente al menos dos años antes del ejercicio de la acción y que vengan ejerciendo de modo activo las actividades necesarias para alcanzar los fines previstos en sus estatutos. 3. ${ }^{\circ}$ Que según sus estatutos desarrollen su actividad en un ámbito territorial que resulte afectado por el daño medioambiental o la amenaza de daño. c) Los titulares de los terrenos en los que deban realizarse medidas de prevención, de evitación o de reparación de daños medioambientales. d) Aquellos otros que establezca la legislación de las comunidades autónomas. 2. Los interesados podrán formular las alegaciones que estimen oportunas y aportar la información que consideren relevante, debiendo ser consideradas por la autoridad competente a la que se dirijan. 3. La autoridad competente dará audiencia a los titulares de los terrenos a que se refiere el apartado $1 \mathrm{c}$ ), al operador y a los demás interesados para que éstos aleguen lo que estimen conveniente o aporten la documentación adicional que consideren oportuna". 


\section{Procedencia de la indemnización de daños cuando la reparación en} naturaleza es imposible.

Ya se sabe que la Ley No 19.300 consagra el principio de la responsabilidad ambiental que ordena que toda aquella persona, natural o jurídica, privada o pública, que dolosa o culposamente causa un daño ambiental, queda obligado a repararlo materialmente a su costo, si ello fuera posible, e indemnizarlo (artículo 3). Y la Ley contiene una concepto de reparación que se aviene perfectamente con la peculiaridad del bien jurídico lesionado, definiéndola como "la acción de reponer el medio ambiente o uno o más de sus componentes a una calidad similar a la que tenian con anterioridad al daño causado o, en caso de no ser ello posible, reestablecer sus propiedades básicas " ${ }^{\prime 30}$. La Ley privilegia la reparación material del daño, la que puede asumir cualquiera de estas dos formas según sea o no posible el restablecimiento del medio ambiente a una calidad similar a la anterior al daño causado; a esas dos acciones copulativamente se refiere el artículo 3 cuando explica en qué consiste la responsabilidad por el daño ambiental y condiciona su procedencia a que ambas sean posibles. Agrega la norma que el responsable del daño ambiental quedará obligado a una indemnización conforme la Ley .

La Ley No 19.300 no prevé reglas sobre la indemnización de daños, ni para el daño ambiental, ni menos para el daño civil; la indemnización del daño se rige completamente por el derecho común contenido en el Código Civil. De lo que se trata aquí es de resolver sobre si el régimen de la Ley No 19.300 admite la indemnización del daño ambiental cuando su reparación material no sea posible en los términos del artículo 2 letra s). Y ello pasa por preguntarse sobre la eficacia de la protección del medio ambiente frente de una lesión al mismo probadamente imputable a la acción u omisión culpable de otro; $y$, consiguientemente, sobre la función de prevención de este orden de responsabilidad ${ }^{31}$. Y lo digo porque, como lo reconoce la doctrina más autorizada, no será extraño que no sea posible la reparación material del daño ambiental, al menos en una parte ${ }^{32}$. Ya el

${ }^{30}$ Cfr. Bermúdez Soto, J., cit. (n. 2), pp. 242-243. El autor asevera que "la LBGMA. intenta entregar una solución que se ajuste a los requerimientos propios del bien jurídico que se trata de proteger y reparar". Y posteriormente explica el alcance de la definición legal de "reparación", distinguiendo la reposición en una calidad similar y el reestablecimiento de las propiedades básicas. El autor concluye que ante la imposibilidad de una reparación in natura como la del derecho civil, el legislador prevé una reparación material en equivalente.

${ }^{31}$ Sobre la función de prevención de la responsabilidad ambiental, véase: BARRos Bourie, E., cit. (n. 5), pp. 789 y 790.

${ }^{32}$ Así se recoge en Bermúdez Soto, J., cit. (n. 30). 
mismo concepto de reparación prevé la imposibilidad del restablecimiento del medio ambiente a una calidad similar; conformándose con la reposición de las propiedades básicas; lo que indudablemente implicará que una parte del daño ambiental irrogado quedará sin reparación. Se corre el riesgo de que una interpretación estrecha de la norma sea vista como un incentivo para contaminar, dado que si se sabe de antemano que si la reparación material no es posible, la Ley renuncia a la responsabilidad, convirtiéndose en letra muerta, al no convertirse la reparación material en una indemnización del daño.

En la doctrina hay acuerdo, sin una mayor reflexión a mi juicio, en orden a que la Ley al definir la responsabilidad como una acción de reparación material, habría excluido la indemnización cuando tal acción no fuere posible, argumentándose que en realidad el precepto [artículo 2 letra s)] habría previsto una regla expresa para la imposibilidad de una reparación en naturaleza (reposición del medio ambiente a una calidad similar), instaurando una reparación material en equivalencia: el restablecimiento de las propiedades básicas del medio ambiente dañado. De este modo, sería la propia Ley la que habría excluido la indemnización de daños como manifestación de la responsabilidad ambiental, que se limitaría a una reparación material en todo caso $^{33}$.

En el derecho comparado, hay sistemas, como el derecho italiano, en el que se obliga al responsable del daño a una indemnización que ingresa a un fondo especial para la conservación del medio ambiente ${ }^{34}$; y otros, como el derecho español, al responsable queda obligado a la adopción de medidas de reparación o reparadoras, excluyendo la indemnización de daños y previendo un sistema de ejecución forzada de tales medidas, con la posibilidad que sea la propia autoridad administrativa la que actúe y posteriormente traslade los costos de las medidas al responsable. Este último régimen se basta a sí mismo, prescindiendo del recurso a las normas del

${ }^{33}$ Véase: Bermúdez Soto, J., cit. (n. 30), pp. 245-246. La tesis del autor es la siguiente: "la responsabilidad ambiental strictu sensu, es decir, aquella que busca la reparación del medio ambiente dańado, sólo se traduce en las dos formas de reparación ya apuntadas anteriormente, no siendo procedente por esta vía la indemnización de perjuicios”. En la misma dirección: Barros Bourie, E., cit. (n. 5), pp. 811-812. En su obra se lee: "La eficacia de la acción está condicionada por la posibilidad de reparar el medio ambiente dańado" y agrega: "la que está excluida (la indemnización) en el caso de la acción por daño ambiental puro".

${ }^{34} \mathrm{El}$ artículo 18, párrafo (1) de la Ley No 394, de 8 de julio de 1986, sobre el Ministerio del Medio Ambiente y normas en materia de daño ambiental, impone al que dolosa o culposamente irroga un daño al medio ambiente la obligación de indemnizar al Estado, la que quedará afecta a una finalidad ambiental. 
Derecho civil de la responsabilidad como derecho supletorio ${ }^{35}$.

La cuestión entonces es: ¿qué sucede en la Ley No 19.300? ¿Ella excluye la indemnización de daños o bien ésta procedería por aplicación de las normas del derecho común y supletorio cuando fuese imposible total o parcialmente la reparación material del artículo 2, letra s)? Varios son los argumentos en apoyo a la procedencia de la indemnización, planteándose, eso sí, un problema: el destino del dinero objeto de la indemnización.

i) Primero, un argumento de texto. El artículo 3 de la Ley considera la indemnización y no se refiere a la del daño civil, sino a la del daño ambiental. A la indemnización del daño civil se refiere en forma expresa el artículo 52 de la Ley . El artículo emplea la conjunción copulativa "e", infiriéndose que una reparación material y una indemnización son perfectamente compatibles y que pueden acumularse, eso sí respetando la medida del daño ambiental irrogado; y si la primera no fuere posible del todo, como lo prevé expresamente la norma, procedería en forma exclusiva la indemnización del daño ambiental como una reparación en equivalencia. El artículo 3 obliga a una indemnización conforme a la Ley, cobrando especial importancia lo dispuesto por el artículo 51, que hace aplicable las disposiciones del título $35^{\circ}$ del libro IV del Código Civil, las que obligan al responsable de un delito o cuasidelito al pago de una indemnización.

ii) Segundo, la función de prevención especial y general que debe cumplir la responsabilidad ambiental, la que se vería en entredicho si sus propias normas la limitan a una reparación en naturaleza, renunciando a una en equivalente. Si las cosas se llevan a un extremo, los operadores encontrarían un gran incentivo para causar daños ambientales, burlando

${ }^{35}$ En la nueva Ley de responsabilidad medioambiental española se prevé un régimen de responsabilidad administrativa inspirada en los principios de prevención y del que contamina paga y que obliga a los operadores de actividades económicas o profesionales a la adopción de medidas, de prevención y de evitación de daños ambientales, de una parte; y de reparación de otra. En lo que concierne a las medidas de reparación, la Ley las define en su artículo 2, numeral 16, como "toda acción o conjunto de acciones, incluidas las de carácter provisional, que tenga por objeto reparar, restaurar o reemplazar los recursos naturales y servicios de recursos naturales dañados, o facilitar una alternativa equivalente"; y su artículo 20 prescribe que cuando se hayan producido dańos medioambientales, el operador queda obligado a ponerlo en conocimiento de la autoridad y debe: (i) adoptar todas aquellas medidas provisionales necesarias para, de forma inmediata, reparar, restaurar o reemplazar los recursos naturales y servicios de recursos naturales dańados; informando a la autoridad competente de las medidas adoptadas; (ii) someter a la aprobación de la autoridad competente una propuesta de medidas reparadoras de los dańos medioambientales causados. En la resolución que declare la responsabilidad medioambiental del operador, se fijarán las medidas de prevención, evitación o reparación según corresponda; tomando en cuenta la propuesta hecha por el operador responsable (artículo 45). 
el principio de responsabilidad contenido en la Ley .

iii) Tercero, las indemnizaciones de daños no son del todo ajenas al régimen de la Ley $\mathrm{N}^{\circ} 19.300$. Ésta se limita a definir lo que se entiende por reparación del daño ambiental, sin precisar los efectos que se siguen de la inejecución de las medidas de reposición o reestablecimiento ${ }^{36}$. Ante esta omisión sólo resta acudir al estatuto de las obligaciones de hacer y, en especial, al precepto del artículo 1553 del Código Civil, complementado por las normas procesales del Código de Procedimiento Civil para la ejecución de esta clase de obligaciones ${ }^{37}$. Si se incumple la obligación de hacer, bien se llegará a su ejecución por un tercero a costa del deudor; o a una indemnización compensatoria, a elección del que hubiere obtenido en el juicio. En este supuesto igualmente se llega a una indemnización de daños. A lo anterior se suma que el artículo 15 de la Ley, autorizar la ejecución anticipada de cualquier proyecto o actividad que deba someterse a un estudio de impacto ambiental, siempre que su responsable presente una póliza de seguro que cubra el riesgo por daño al medio ambiente; y el Reglamento del Sistema de Estudio Impacto Ambiental prescribe que tal seguro cubrirá el daño ambiental y que si el riesgo se realiza la indemnización ingresará al Fondo de Protección Ambiental, quedando afectada a la reparación del daño ambiental causado. No obstante lo anterior la aseguradora siempre podrá evitar el pago de la indemnización si repara materialmente a su costo el daño ambiental ${ }^{38}$.

iv) Se dice que una de las razones para negar lugar a la indemnización

${ }^{36}$ La regulación es deficiente y contrasta con la Ley española que prevé una responsabilidad medioambiental que se manifiesta exclusivamente en medidas de prevención, evitación y reparación de daños medioambientales. El artículo 47 prescribe sobre la ejecución forzosa en caso de incumplimiento: "1. En caso de incumplimiento, las resoluciones administrativas que impongan el deber de realizar las medidas de prevención, de evitación y de reparación de daños medioambientales serán objeto de ejecución forzosa, previo apercibimiento. Dicha ejecución podrá ser instada por los interesados. 2. La autoridad competente procederá a la ejecución subsidiaria, especialmente cuando el daño medioambiental sea grave o la amenaza de daño sea inminente. 3. Cuando se estimara conveniente por no comportar retrasos que puedan poner en peligro los recursos naturales afectados, la autoridad competente podrá imponer sucesivamente hasta un máximo de cinco multas coercitivas, cada una de ellas por un importe máximo del diez por ciento del coste estimado del conjunto de las medidas en ejecución".

${ }^{37}$ Cfr. Barros Bourie, E., ibíd: "debe entenderse que la reparación da lugar a una obligación de hacer que civilmente está sujeta a las reglas de ejecución del artículo 1553 del Código Civil y de los artículos 530 y siguientes del Código de Procedimiento Civil".

${ }^{38}$ Véanse los artículos 107 a 111 del Reglamento del Sistema de Estudio de Impacto Ambiental (D.S. No 95, de 2001, Ministerio Secretaría General de la Presidencia de la República (DO. 7 de diciembre de 2002)). 
es la dificultad, sino la imposibilidad, de valorar el daño ambiental, lo que impediría que la indemnización cumpliera la función compensatoria que le es propia. Si se está de acuerdo que todo el que dolosa o culposamente causa un daño ambiental debe repararlo, por ser ésta una concreción más del principio de la reparación integral, la dificultad e incluso la imposibilidad de valoración no puede constituir un obstáculo para ordenar su indemnización en caso no ser posible su reparación material. Podría asimilarse este daño ambiental al daño moral y asignarle a su indemnización, no una función compensatoria, sino de satisfacción, en términos de considerar a la indemnización como un valor de reemplazo que permita desatender al daño ambiental irreparable, y asignarlo a un fin de preservación o conservación medio ambiental. Tal función en el caso del daño moral ya se encuentra instalada en la doctrina y jurisprudencia nacionales y surge dado que la indemnización del dańo moral, que nadie discute su procedencia, no se avenía con la función compensatoria o de justicia correctiva de la indemnización de los daños patrimoniales. Siendo así, en la fijación de la indemnización del daño ambiental, deberán considerarse especialmente, tal como ocurre en el caso del daño moral, la gravedad del hecho y las facultades económicas del agente contaminador.

Ya se anticipó que si se acepta la procedencia de la indemnización del daño ambiental cuando su reparación material sea imposible al menos parcialmente, surge un problema adicional, el referido al destino del valor en que ella se traduce. A mi juicio, el titular de esta indemnización debiese ser el Estado como garante del derecho fundamental garantizado a todos por la Constitución, o bien el órgano de la Administración del Estado al que la Ley ha encomendado concretamente el cumplimiento de deber estatal de la preservación del medio ambiente. Así como en el caso de la indemnización del seguro ambiental del artículo 15, la indemnización debiese ingresar al Fondo de Protección Ambiental del artículo de la Ley. Es el Estado y sus órganos, en virtud del mandato constitucional, los que deben velar por el correcto destino que se asigne a las indemnizaciones de daño ambiental (artículo 68 Ley 19.300). De lo anterior se sigue que si es cualquier persona afectada por el daño ambiental que demanda su indemnización de daños en forma subsidiaria, deberá pedirlo a beneficio del Estado o del Fisco y no al propio, dado que ello implicaría un enriquecimiento sin causa. 


\section{CONCLUSIONES}

a) Un daño ambiental puede producir como consecuencia directa e inmediata un daño civil, naciendo dos acciones plenamente compatibles, la de responsabilidad ambiental y la indemnizatoria ordinaria. Tales acciones podrán ejercitarse conjuntamente o en forma separada. La opción pertenece a la víctima del daño civil.

b) La Ley No 19.300 prevé un régimen primario o básico de común aplicación a ambas responsabilidades, régimen que hace excepción a las normas del derecho común del Código Civil.

c) La Ley da reglas especiales para la legitimación activa de la acción ambiental, reconociéndola a las personas naturales o jurídicas que hayan sufrido un daño ambiental; al Estado a través del Consejo de Defensa del Estado y a las Municipalidades cuando así sean requeridas por cualquier persona.

d) La responsabilidad ambiental tiene por primer objeto una prestación de hacer, la reparación material del daño en la medida que sea posible. Sin embargo, cuando tal reparación material, en los términos previstos por la propia Ley, no es posible total o parcialmente, se abre paso, por aplicación del artículo 3 de la Ley y las normas de derecho común, la indemnización de daños como una reparación en equivalencia.

[Recibido el 7 y aceptado el 12 de diciembre de 2007].

\section{BIBLIOGRAFÍA}

Abeliuk Manasevich, R., Las obligaciones (Santiago, 2003).

Alessandri Rodríguez, A., De la responsabilidad extracontractual en el Derecho Civil chileno (Santiago, 1943).

Barros Bourie, E., Tratado de la responsabilidad extracontractual (Santiago, 2006).

Bermúdez Soto, J., Fundamentos de Derecho Ambiental (Valparaíso, 2007).

Bermúdez Soto, J., La responsabilidad extracontractual de la Administración del Estado por falta de servicio y por el daño ambiental, en RDUCV. 23 (2002).

Bordalí Salamanca, A., Tutela Jurisdiccional del Medio Ambiente (Valdivia, 2005).

Corral Talciani, H., Lecciones de responsabilidad extracontractual (Santiago, 2004).

De La BARRa GiLI, F., Responsabilidad extracontractual por daño ambiental: el problema de la legitimación activa, en RChD. 29 (2002) 2.

Domínguez Águila, R., La prescripción extintiva. Doctrina y jurisprudencia (Santiago, 2004). 
Hunter Ampuero, I., La culpa con la Ley en la responsabilidad civil ambiental, en RdUACh. 18 (2005) 2.

Somarriva Undurraga, M., Las obligaciones y los contratos ante la jurisprudencia (2a edición actualizada por Domínguez Águila, R., Santiago, 1984).

Tapia Suárez, O., De la responsabilidad civil en general y de la responsabilidad delictual entre los contratantes (Concepción, 1941, en reimpresión a cargo de DiEZ Schwerter, J., Santiago, 2006).

Valenzuela Fuenzalida, R., El que contamina paga, en Revista de la cepal 45.

Valenzuela Fuenzalida, R., Nociones acerca del principio "El que contamina paga", en Memoria del Seminario de Derecho Ambiental (Santiago, 1994). 